\section{Engaging Stakeholders: The Next Challenge in Corporate Environmental Reporting}

SustainAbility has recently embarked on the third phase of its work with the United Nations Environment Programme (UNEP). Our aim: to focus on >Stage 5< sustainable development reporting and stakeholders. Below, Andrea Spencer-Cooke, SustainAbility's Programme Manager, reviews the progress to date.

Almost exactly five years ago, the first voluntary corporate environmental report was published. Sensing a new approach was needed to the way in which companies and their stakeholders engage on environmental issues, Norsk Hydro UK took the first step towards scoming clean <: they produced a > warts-and-all $<$ report on the company's environmental performance. This move pioneered what, five years on, has become one of the most powerful symbols of corporate commitment to the environment - the freestanding corporate environmental report (CER). In the short period since that first report appeared, progress has been astonishing. Admittedly, corporate environmental reporting is still limited to a relatively small number of companies: our 1994 SustainAbility Survey of the Fortune 100 Companies found that only $23 \%$ of these were producing a CER - and the number of small and medium sized enterprises (SMEs) reporting is even smaller. But what has changed drastically is the quality of disclosure in the reports that are produced.

\section{Towards a Reporting Taxonomy}

Like biologists confronted with vast new treasures of uncatalogued biological diversity, we need to identify and understand the order underlying evolving reporting practice. Coming Clean, SustainAbility's first international survey of corporate environmental reporting, was produced jointly in 1993 with Deloitte Touche Tohmatsu International (DTTI) and the International Institute for Sustainable Development (IISD). One key feature of this study was a five stage reporting model, running from so-called >green glossies< at Stage 1, through to full-blown sustainable development reporting at Stage 5. This was our first attempt to develop a >taxonomy< of reporting.

Building on this, UNEP Technical Report No. 24, entitled Company Environmental Reporting: a Measure of the Progress of Business and Industry Towards Sustainable Development, appeared in 1994 and was the result of a joint UNEP/SustainAbility project focusing on international reporting trends. Using our 5-stage reporting model, 100 corporate environmental reports were ranked and then sreverse engineered $<$, to spot the key reporting ingredients and track the various reporting >recipes< being used. 50 separate reporting ingredients, from policy to mass balance and stakeholder relations, were identified.

Of the 100 companies surveyed, only $5 \%$ had reached Stage 4, with most hovering somewhere between Stages 1 and 2. More importantly, many of the reports did not even contain the 20 minimum key features that we identified as core reporting elements. Significantly, no-one had reached Stage 5, namely, > sustainable development reporting linking environmental, economic and social aspects of corporate performance, supported by indicators of sustainability<

\section{The Coming Convergence: Where the Rhine Meets the Atlantic}

Reports appearing in 1995 show a rather different picture. Not only have a number of companies moved up one - or even two - stages, with more reporting ingredients being used, but companies are now setting themselves more rigorous targets and objectives, often with a commitment to track their environmental performance against these. Environmental management systems (EMS) are winning a more central role and there is considerably more quantification, with the > serial< reporters now able to benchmark their progress over time.

Moreover, the significant regional distinctions in reporting practice identified in our previous surveys are beginning to blend. The UNEP report contrasted the $>$ Anglo-Saxon $<$ model, which focuses upon management systems and inventories and is favoured by most North American and UK companies, with the >Rhine model, used by many Scandinavian and German companies and based on an eco-balance of environmental inputs and outputs across the life-cycle of the reporting company's operations.

German reports, formerly focused on a >mass balance $<$ approach to reporting, are now also featuring information on management systems and performance data. Likewise, some of their Anglo-Saxon counterparts, used to the semissions inventory approach, are beginning to adopt elements of a life-cycle approach in their reports.

In both regions, life cycle analysis (LCA) occupies a growing place, while, particularly in North America, design for the environment (DFE) is becoming a key component, with companies such as AT\&T and Xerox giving it a prominent place in their 1994 reports. So far, however, few companies have developed fullyblown environmental performance indicators (EPIs) along the lines of Novo Nordisk's >ecoproductivity index , but this is on the rise. Another issue that is bound to gain ground - but is presently touched on by few companies other than benchmarking leaders such as Xerox - is >environmental benchmarking $<$.
A further trend is the integration of environmental with annual financial reporting. This year, companies as varied as BP, Danish Steel, Inveresk, and Norsk Hydro all featured significant amounts of environmental information in their annual report and accounts. Increasingly, environmental liabilities, compliance and prosecutions are also being discussed.

A growing number of reports are being independently verified, too. Interestingly, a regional distinction between Europe and North America is emerging in this area. The most recent CERs of Ciba, Dow Europe, Neste, and Novo Nordisk are all independently verified, with the report itself being signed off by a third party. By contrast in the US, verification statements such as those featured in the Bristol-Myers Squibb (1995) and Dupont (1994) reports, refer to the audit system the company has in place, not the CER.

With no consensus over standards and qualifications for verifiers, there are wide disparities in the way reports are currently being signed off. In Europe at least, the recent entry into force of the EC Environmental Management and Audit Scheme (EMAS) will have an impact upon both the structure and content of reporting and verification. The compulsory Environmental Statement required under EMAS will go some way towards standardising the type of information being reported - at least at site level - while the accreditation of verifiers is expected to bring some degree of harmony into that process. That said, however we are still a very long way from the promised land of a universal reporting framework.

\section{Unfinished Business: Spotting the Gaps}

The latest crop of reports still displays significant shortcomings, notably in terms of core relevance, consistency, comprehensiveness and comparability. In the absence of meaningful performance indicators and benchmarking, CERs remain notoriously difficult to compare, fuelling calls, by groups such as Greenpeace and the Panel of Judges for the 1994 Chartered Association of Certified Accountants (ACCA) Environmental Reporting Awards Scheme, for mandatory reporting standards.

Whilst reporting against targets has improved, there are still many companies setting goals that either cannot be measured or have no time frame for achieving them. This makes performance hard to assess.

In addition, too few companies adequately address the environmental impact of their core business activities, limiting their reporting instead to so-called >good housekeeping « measures. The banking sector is a good example of this: whilst more banks, from NatWest in the UK, to SBS in Switzerland, are now producing CERs, virtually none of them talk about the impact on the environment of their credit and investment policies. Yet it is clearly here that their major impact lies. 
The UNEP report identified as its fifth cluster of reporting ingredients $>$ the sustainable development agendar. Most companies still have a long way to go with improving the most basic environmental reporting features, let alone dealing satisfactorily with the elements that make up this cluster, namely, global environment and development issues, global operating standards, technology co-operation - and stakeholder dialogue. This is still largely uncharted water where CERs are concerned.

\section{Held To Account}

The UNEP report predicted that the corporate >responsibility < agenda of the 1970s and 1980s would evolve into a more demanding >accountability < agenda in the early 1990s, moving finally towards a >sustainability agenda as we approach the 21 st century. Although reporting clearly still has far to go, what is also clear is that a momentum is gathering which places transparency, accountability and dialogue right at the heart of good corporate citizenship. The CER is more of a process than a product: once companies commit themselves to external reporting, they find it difficult to turn back. In this new culture of openness, non-reporters will find their stance increasingly hard to defend.

When the first CERs hit the streets, shudders went through the boardrooms of major companies across the globe. First-time reporters steeled themselves for the fallout from unprecedented disclosures that did not always paint a pretty picture of their environmental impact. Most were therefore amazed to find themselves being congratulated, not criticised, for their new openness. With slowly growing confidence, companies have now realised they are not going to be pilloried for scoming clean«. But as more and more companies report, stakeholders' expectations are also building. And companies should expect to see their reports increasingly being benchmarked by third parties.

\section{The Next Challenge: Engaging Stakeholders}

Sensing that the >omnibus « report may have run its course, companies are considering how to >fine-tune reporting to specific stakeholder groups. The question now preoccupying most reporting companies is who are the key target audiences and what do they want to know? To date, few stakeholders have made their information needs explicit and it is unclear how corporate environmental reports are actually being used.

Our 1993 report, Coming Clean, identified the main audiences for environmental reports (in order of importance) as employees, legislators \& regulators, local communities, investors, suppliers, customers, consumers and industry associations, with environment groups, surprisingly, education and the media low on the priority list. SustainAbility's work in this area indicates that currently, the priorities are being redefined, with customer and supplier pressures growing, increased interest in the financial community and environmental groups beginning to respond and make their needs felt. Stakeholders are becoming more critical and focused in their demands. Against this background, organisations will increasingly have to > fine-tune < their reporting to specific audiences.

SustainAbility, supported by UNEP, is currently tackling these questions under our $>$ Engaging Stakeholders programme. Our aim is to bring together interesting and innovative case studies on how key audiences are being reached and how stakeholder groups are actually making use of CERs. A better understanding of new stakeholder expectations and emerging agendas is a vital starting point for expanding and improving the reporting process - and for spurring the transition towards sustainable development reporting.

\section{Opening up the Black Box: The 3E's}

At the June 9 UNEP Industry and Environment Programme Activity Centre (UNEP/IEPAC) Industry Association Meeting held in Paris, a roundtable was held on corporate environmental reporting and the forthcoming SustainAbility/UNEP work programme. In our presentation, John Elkington, who is SustainAbility's Chairman and Director of the corporate environmental reporting programme, and I set out what we see as the emerging agenda for the next five years. The sustainability transition will require companies to widen their horizons to embrace the 3 E's: the economy, the environment and the social equity dimensions of development. This shift is already reflected in the rising interest in social auditing and illustrated by a growing number of reports on social issues so far produced by companies like the Body Shop, SBN Bank, Skandia and Traidcraft.

Our work programme will be made up of two parts, the first of which, >Engaging Stakeholders`, will explore the >syncromesh those making reports and those actually using them. This phase will:

- illustrate stakeholder uses of corporate environmental reports (CERs)

- outline emerging or outstanding needs and expectations

- describe gaps and areas for improvement.

The second phase of our work, on Stage 5 reporting, will:

- provide an overview of key developments in the corporate environmental reporting debate

- discuss latest practice in the field

- create a new CER ranking table

- provide best practice examples

- build on the work already accomplished to generate new insights into possible elements of sustainable development reporting.

The $>$ black box \& of sustainable development reporting needs to be approached like a Russian doll; no single company can do it alone. The next five years will usher us into the new millennium, spurring a shift from >accountability< to ssustainability<. As this new agenda unfurls, corporate reporting will need to fit into sectoral reporting, which in turn must slot into national and ultimately, global, sustainable development reporting.

SustainAbility's work in this area is driven by the conviction that reporting is a critically important lever for change in the direction of improved environmental performance and, longer term, sustainability. The next great challenge is how to build the dialogue, fora and processes which ensure that reporting does in fact lead to real environmental - and increasingly, social progress.

Andrea Spencer-Cooke, London

Information: If you are interested in SustainAbility's corporate environmental reporting programme, or wish to share experience in this field, please get in touch with Andrea Spencer-Cooke, the Programme Manager, or John Elkington, Programme Director. Our corporate environmental reporting surveys, Coming Clean, Company Environmental Reporting and the 1993 Fortune 100 Survey can be obtained from SustainAbility Ltd, The People's Hall, 91-97 Freston Rd, London W11 4BD, UK.

Ein Umweltbericht / eine Umwelterklärung sollte auf jeden Fall Aussagen zu den folgenden Punkten enthalten:

1) Vorwort der Unternehmensleitung

2) Kurzbeschreibung der Unternehmenstätigkeit

3) Umweltpolitik des Unternehmens in Form von Umweltleitlinien oder Umweltgrundsätzen

4) Organisation des Umweltmanagementsystems

5) Systematischer Überblick über die Stoff- und Energieströme

6) Bewertung der umweltrelevanten Stoff- und Energieströme

7) Wichtige Umweltfragen in bezug auf Produkte und Dienstleistunen

8) Umweltprogramm

9) Ansprache der wichtigsten Adressaten

10) Formanangaben (Ansprechpartner im Unternehmen, Umweltgutachter etc.)

Aus: Jens Clausen, Klaus Fichter, Frieder Rubik: Umweltberichte/Umwelterklärungen von Unternehmen. Anforderungen und internationaler Überblick publizierter Berichte. IÖW-Diskussionspapier 33/95 
(c) 20I0 Authors; licensee IÖW and oekom verlag. This is an article distributed under the terms of the Creative Commons Attribution Non-Commercial No Derivates License (http://creativecommons.org/licenses/by-nc-nd/3.o/), which permits unrestricted use, distribution, and reproduction in any medium, provided the original work is properly cited. 